\title{
Research on Heat Conduction Inverse Problem of Continuous Long Downhill Truck Brake
}

\author{
Shun Zeng ${ }^{1,}$, Heng Zhang $^{2, b}$, Yunwei Meng ${ }^{1, c}$ \\ ${ }^{1 .}{ }^{3}$ China Merchants Chongqing Communications Research \& Design Institute, Chongqing \\ 400067, China \\ ${ }^{2}$ Chongqing JiaoTong University, Chongqing 400067, China. \\ aemail:zengshun@cmhk.com, 'email: 5049214@qq.com, cemail:514346081@qq.com
}

Keywords:Brake temperature, Continuous Long Heavy Down, Heat Conduction, Inverse Problems Abstract:Brake temperature rise has a significant impact on the braking performance of the vehicle, especially when the vehicle in the long downhill road, and the driver of the vehicle brake operating temperature is particularly necessary to master. Inverse heat conduction problem solving was based on the thermal conductivity of the positive results of the problem solving, when the brake drum temperature field problems being solved to EQ1141G truck rear drum brakes for the study, using ABAQUS finite element simulation software obtained repeated braking condition of the brake drum transient temperature field, enabling drum brakes during braking temperature field simulation. By the conjugate gradient method to establish a brake drum inner wall temperature inversion model to achieve MATLAB calls ABAQUS simulation software to build a complete brake drum inner wall temperature inversion program proved that the use of the theory of heat conduction problems related to inversion system the distribution of the effectiveness of the stationary drum inner wall temperature.

\section{Introduction}

When a vehicle runs on a continuous downhill road, especially for large trucks, we need to frequent braking, to ensure that the driving speed is maintained at a reasonable range of the desired speed. When the truck brake, brake shoe friction contact with the inner surface of the brake drum, making the brake drum temperature raise, because the friction surface is not exposed in the air, and the friction heat generated can not be cooled in time. Frequent braking if prolonged, continuous high temperature brake drums, brake "hot dip" phenomenon occurs, when the friction linings when the temperature exceeds $290^{\circ} \mathrm{C}[1]$, the friction linings gradually broken, carbonized, and even lead to complete truck brakes fail, causing traffic accidents. Statistics show that in vehicle accidents grown continuously downhill types, trucks accounted for $60 \%$ to $80 \%$, from the cause of the accident, the traffic accidents caused by brake failure caused by $63 \%$ [2]. Currently, the traditional means of measuring the internal temperature of the brake drum brake is usually installed inside the thermocouple, the measuring method has some drawbacks, as a result of the harsh environment caused by thermocouple measurements easily damaged, can not fully reflect the distribution of brake temperature, cost higher, etc., is not conducive to the promotion and application.

Inverse Heat Transfer Problems refers to the temperature measurement information via the study of boundary conditions or part of the surface, the use of reasonable inversion algorithm to determine the intensity of the heat source, heat flux, temperature and internal geometry and other unknown characteristic parameters a class of problems.[3] Lesnic D and Elliott L, et al using regularization method for solving one-dimensional unsteady heat conduction plate inverse problem of heat flux and temperature inversion.[4] Su J and Silva Neto A J. et al., Levenberg-Marquardt 
algorithm by inversion of the tube wall heat flux in turbulent flow.[5] Soochow University in 2012 by Wang Chunyan organization and uniform heat transfer model constructed hierarchically organized biological heat transfer, heat biological tissue predicted depth and temperature information.[6] In 2011, Professor Li Tao Beijing University of Chemical Technology and Student thermal model based on positive issues finite element method to construct the pipe, elbow, and inverse heat conduction problem from the perspective of using the conjugate gradient method established by means of the inner wall of the outer wall temperature inversion temperature the inverse heat conduction model.[7][8]

In this paper, based on inverse problems for heat transfer wall temperature of the brake drum Identification: The brake drum outer surface temperature information more accessible, the theory of heat transfer through to the inversion problem is the anti brake drum inner wall temperature. This method avoids the shortcomings of traditional measurement methods, and the inversion results obtained by this method can comprehensively reflect the brake drum temperature distribution.

\section{Influencing Factors truck braking performance}

At present, various types of vehicles used by friction brake into the drum and disc types. High performance drum brake, to ensure the stability and safety of the vehicle when braking. Thus, the vast majority of large passenger cars brake and drum brakes for heavy-duty truck.

\section{1) Influence of friction lining wear on braking safety}

When the braking system does not work, there is a working gap between the friction lining and the brake drum, thereby ensuring the free rotation of the brake drum when driving. After a long truck brakes, which increase the amount of brake wear, brake drum and linings of the working gap is increased, so that while the friction coefficient of the friction lining is reduced, and wear when the gap is too large, the vehicle's own brake wear compensation device Unable to make the linings timely fit brake drum, which occurred in the brake delays. With increasing use of time brake friction lining material will gradually fall off, the higher the temperature of the brake, the more serious wear and tear, the wear rate of brake drums and linings of the greater friction linings and brake drum the gap will gradually become larger, thereby increasing the braking time, the emergence of the brake hysteresis.

\section{2) Effect of friction torque brake safety}

Braking of the vehicle, the brake system will be actuator driver pedal force to the wheel brake cylinder and the brake line pressure. Brake line pressure to brake shoes and brake drum frictional contact, friction torque, so as to achieve the braking effect. Braking torque is one of the major factors that influence the braking performance, stable braking torque, brake rotor safety performance of the vehicle and has an important role.

\section{3) Effect of temperature on the brake safety brake}

As the temperature gradually increased, the friction material surface film, the surface of the body will occur physical and chemical changes, thus changing the coefficient of friction. At lower temperatures, the friction coefficient of the friction material increases as the temperature rises, when the temperature rises above a certain limit, the friction coefficient becomes smaller, shown in Fig 1.1 . 


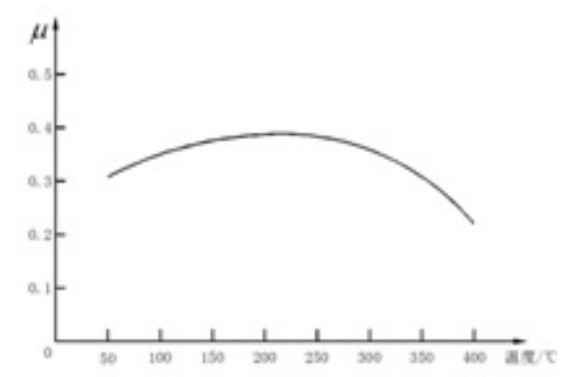

Fig1.1 Friction lining friction coefficientvariation with temperature

Friction material characteristics determine the braking performance of the brake sensitive to temperature, and the coefficient of friction is an important factor in the friction material.

\section{Drum brake temperature field simulation analysis}

According to drum brake heat and thermal analysis, drum brake friction heat change over time, so the brake drum temperature field is a function of time, temperature rise may be considered a non-mathematical model with certain boundary conditions and initial conditions steady-state heat conduction problem, unsteady three-dimensional mathematical model of the temperature field is:

$$
\rho \cdot c \cdot \frac{\partial T}{\partial t}=K \cdot\left(\frac{\partial^{2} T}{\partial x^{2}}+\frac{\partial^{2} T}{\partial y^{2}}+\frac{\partial^{2} T}{\partial z^{2}}\right)
$$

Initial conditions: $\mathrm{t}=0, \mathrm{~T}=\mathrm{T} 0$

Boundary conditions:

(1) The inner surface of the brake drum to accept a time-varying heat flux, namely

$$
-K \cdot\left(\frac{\partial T}{\partial n}\right)_{w}=q_{w}
$$

(2) The presence of the outer surface of the brake drum and ambient radiation heat transfer and convection heat transfer and convection heat transfer coefficient with changing speed, namely

$$
-K \cdot \frac{\partial T}{\partial n}=h^{\prime} \cdot\left(T_{w}-T_{f}\right)+\sigma \cdot F\left(T_{w}^{4}-T_{f}^{4}\right)
$$

among them: $\boldsymbol{\rho}$-Brake drum material density (unit: $\mathrm{kg} / \mathrm{m}^{3}$ ).

$\mathrm{c}$-Brake drum material specific heat capacity (unit: $\mathrm{J} /(\mathrm{kg} \cdot \mathrm{K})$ ).

$\mathrm{T}$-Brake drum instantaneous temperature (unit: ${ }^{\circ} \mathrm{C}$ ).

$\mathrm{t}$-Braking action time (unit:s).

$\mathrm{K}$ - The thermal conductivity material of brake drum (unit: $\mathrm{W} /(\mathrm{m} \cdot \mathrm{K})$ ).

$\mathrm{T}_{0}$-Initial temperature ( unit: $^{\circ} \mathrm{C}$ ).

$\mathrm{x}, \mathrm{y}, \mathrm{z}-$ Node Coordinates.

This paper simulation by ABAQUS finite element analysis software for truck brake drum brake temperature field during thermal analysis.

This paper analyzes the variation truck braking drum brake temperature field by the finite element method, in the case as far as possible in line with the actual conditions, the finite element model, the following hypotheses:

(1) Brake drums and linings for the isotropic material.

(2) Truck brake, brake wear is not considered, and the kinetic energy plus potential energy are converted into heat energy is absorbed by the friction brake, according to the distribution ratio of the friction linings and brake drum.

(3) Friction brake linings and brake drum accord between Coulomb's law, coefficient of friction and friction rate, independent of the contact pressure, only a change in temperature. 
(4) Air does not flow in the brake drum, there is no convective heat transfer.

Brake drum material selection HT250, the brake drum material properties affected by temperature, so consider changes in material properties at various different temperatures.

In this paper, the finite element model of drum brakes bottom-up modeling approach, this article uses ZCAX4, finite element model of the brake drum shown in Fig 2.1. To improve the quality of the unit, use swept mesh method, mesh model after the brake drum as shown in Fig 2.2, the finite element model totaled 55,680 nodes, 10,208 units, the entire grid uniform, no sharp corners.

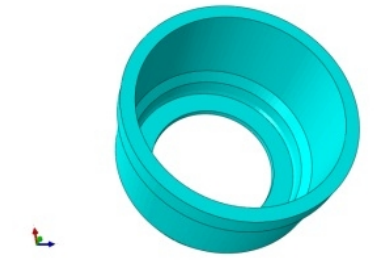

Fig 2.1 Finite element model of the brake drum

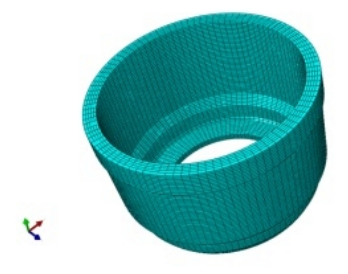

Fig 2.2 Meshing drum brake

As applicable under the actual conditions of the brake, brake braking condition can be divided into three types: one-time emergency braking, brake repeated and continuous braking. To grow more in line with the truck driver downhill braking strategy paper selected for analysis were repeated start condition. Dongfeng EQ1141G7D2 truck for the study.

Repeated braking condition of the vehicle, which is a braking cycle: brake deceleration $\rightarrow$ acceleration $\rightarrow$ constant speed, speed versus time diagram shown in Fig 2.3.

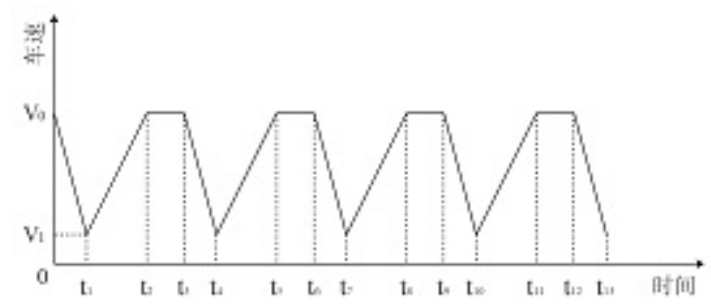

Fig 2.3 Repeat speed varies with time under braking condition schematic

The initial brake temperature is $80{ }^{\circ} \mathrm{C}$, the initial velocity of the vehicle during braking is $65 \mathrm{~km} /$ $\mathrm{h}$, the braking time is $3.3 \mathrm{~s}$, braking deceleration of $3 \mathrm{~m} / \mathrm{s} 2$, speed after braking is $30 \mathrm{~km} / \mathrm{h}$; then accelerated to $65 \mathrm{~km} / \mathrm{h}$, acceleration time of $46.7 \mathrm{~s}$, acceleration $0.21 \mathrm{~m} / \mathrm{s} 2$; then uniform with $10 \mathrm{~s}$, more than once a braking cycle time totaling 60s, repeated 15 times under braking condition braking cycles. Based on the above data, the vehicle can be calculated during braking the brake drum heat flux and convection heat transfer coefficient versus time relationships.

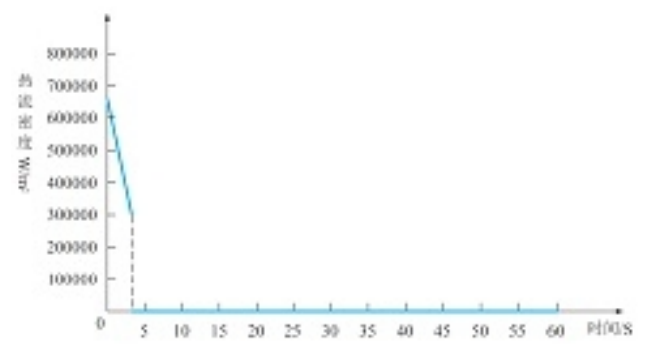

Fig 2.4 A braking cycle heat flux changes

Fig 2.4 shows that at $0 \sim 3.3 \mathrm{~s}$ period of time, the vehicle is braking deceleration state, inner linings and brake drum surface friction generates heat, and with the decline in vehicle speed decreases; in $3.3 \mathrm{~s} \sim 60$ s period, the end of the braking, no friction heat, that friction heat is zero. 


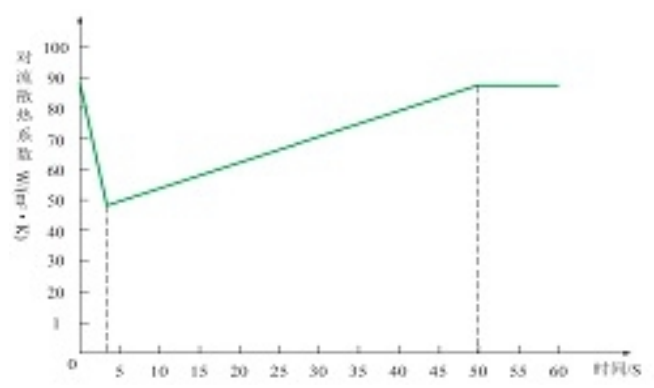

Fig 2.5 A braking cycles convection coefficient of variation

Fig 2.5 from the analysis, the vehicle braking period of $3.3 \mathrm{~s}$, the speed decreases, the convection heat transfer coefficient decreasing; in $3.3 \mathrm{~s} \sim 50 \mathrm{~s}$ time period, the acceleration of the vehicle, when the convection heat transfer coefficient increases the vehicle speed increases; in the $50 \mathrm{~s} \sim 60 \mathrm{~s}$ time period, the vehicle at a constant speed, the convection heat transfer coefficient is constant.

Rear brake drum brake cycle 15 times, the brake drum temperature distribution can be obtained at different times of cloud, the end of braking, ie when $t=900 \mathrm{~s}$, brake drum maximum temperature of 209.2 ${ }^{\circ} \mathrm{C}$, as shown in Fig 2.6, 2.7 .

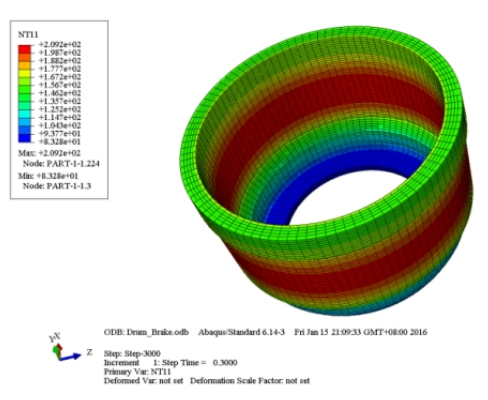

Fig $2.6 \mathrm{t}=900 \mathrm{~s}$ finite element model of the brake drum

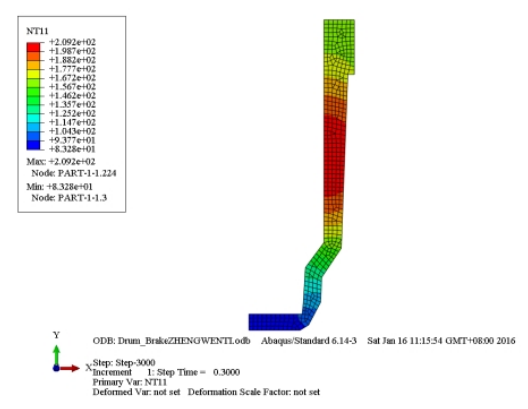

Fig $2.7 \mathrm{t}=900$ s brake drum meshing In order to analyze the temperature distribution in the inner wall of the brake drum, use "PLOT" function to get the temperature distribution $t=900 \mathrm{~s}$ different nodes, the highest temperature of the inner wall of the brake drum brake can be obtained, the node number is 224. As shown in Fig 2.8:

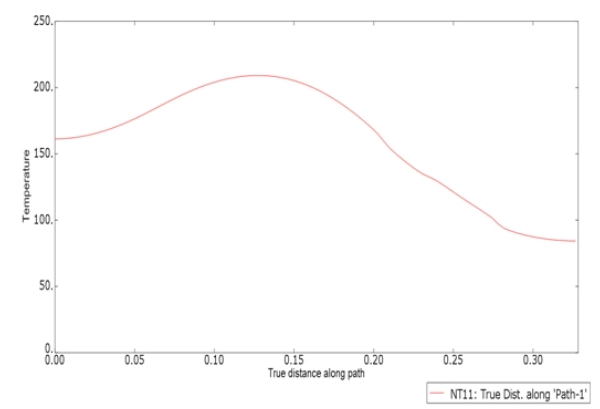

Fig 2.8 The temperature distribution of different node wall cross section $\mathrm{t}=900 \mathrm{~s}$

In order to more directly reflect the node 224 in the radial direction temperature changes, the temperature along the path of the custom node point in the radial direction of the brake drum can be obtained at that point radially inward from the outer edge of each node in the temperature distribution. 


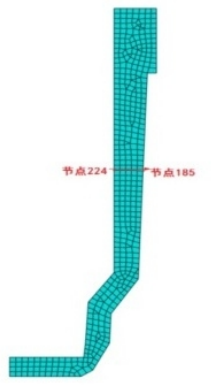

Fig 2.9Radially distributed nodes

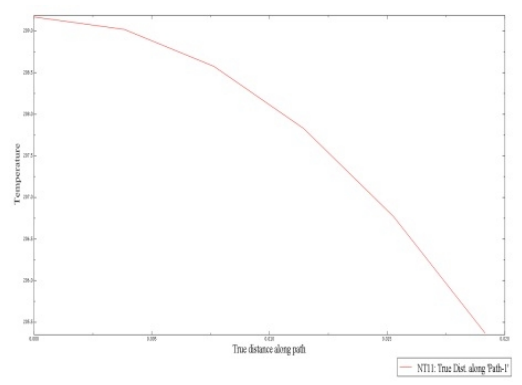

Fig 2.10 temperature distribution node

The inner surface of the brake drum selection node 224 and a radially outer surface of the same node 185 , respectively, can be obtained inside and outside the brake drum surface temperature changes over time, shown in Fig 2.11.

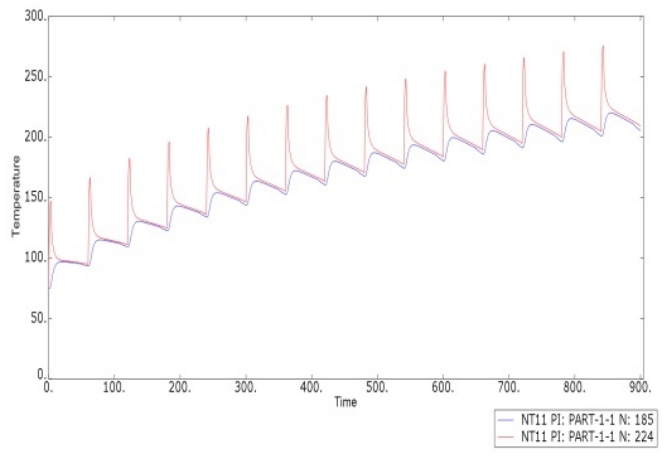

Fig 2.11 node 224 and node 185 temperature changes over time

Taking into account the actual composition of the brake, brake drum temperature of the outer surface of the node 185 is more difficult to measure directly, therefore, easier to obtain selected brake drum outer surface temperature measurement information node 18, and these two temperature change data as biography subsequent chapters calculation.

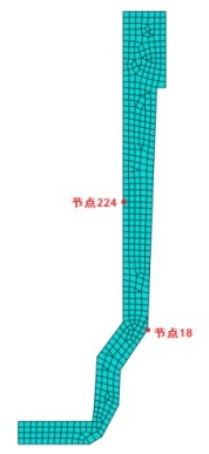

Fig 2.12 The location of the distribution node 224 and node 18

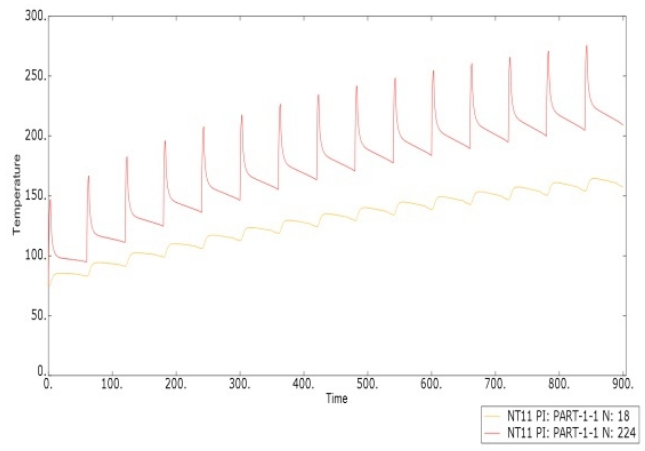

Fig 2.13 node 224 and node 18 temperature changes over time 


\section{Brake drum drum wall temperature inversion based on temperature}

The goal is to use the inverse heat conduction problem of drum wall temperature inversion drum wall temperature measurement. According to the previous section simulation of brake temperature, to brake temperature distribution, and the wall temperature inside the drum, as the exact value of the inverse problem in the calculation and measurement of value, namely the use of the simulated drum wall temperature simulation of wall temperature measurement, the inverse problem as input parameters, calculation of inverse heat conduction problem, drum wall temperature fluctuations, and with the simulation results of drum wall temperature accurately compared to verify the reliability and accuracy of the numerical model.

The process of the change of the surface temperature of a conjugate gradient method for the brake drum can be summarized as follows: firstly, the brake drum surface temperature is measured from the test value; then the surface temperature distribution hypothesis of brake drum, under this assumption, the use of ABAQUS for measuring point temperature value, according to the measurement of the temperature of the outer surface of the brake drum the values and the calculated values, calculate the objective function, determine whether the convergence condition is satisfied; if satisfied, then stop the calculation, if not satisfied, then the brake drum on the assumption that the inner surface of the unknown temperature correction; then through solving ABAQUS a test point temperature value, then calculate whether meet the convergence condition, until the objective function convergence.

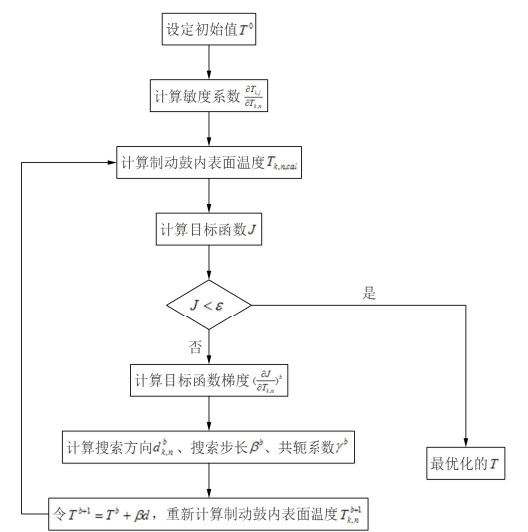

Fig 3.1Schematic diagram of model solving process

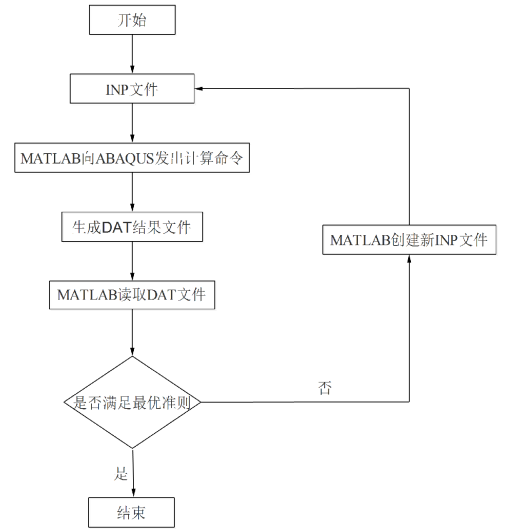

Fig3.2 The general process of MATLAB calling

\section{ABAQUS}

This paper prepared the inverse problem of computing program using MATLAB software, combined with ABAQUS finite element simulation software to calculate the forward problem, and then realize the solution of the brake drum wall temperature prediction model. Therefore, the call of MATLAB ABAQUS simulation software is the key problem of the inversion.

The inversion program written in MATLAB, the above problems can be calculated, the conjugate gradient method inversion of the brake drum inner wall heat flux density. When the point position selection of brake drum wall node 18 , inversion of initial value, measurement error, can be obtained under the condition of the brake drum inner wall heat flux inversion results as shown in Fig 3.3. It can be seen from the Fig, the inversion results and the real value accord better, and has the same fluctuation trend. 


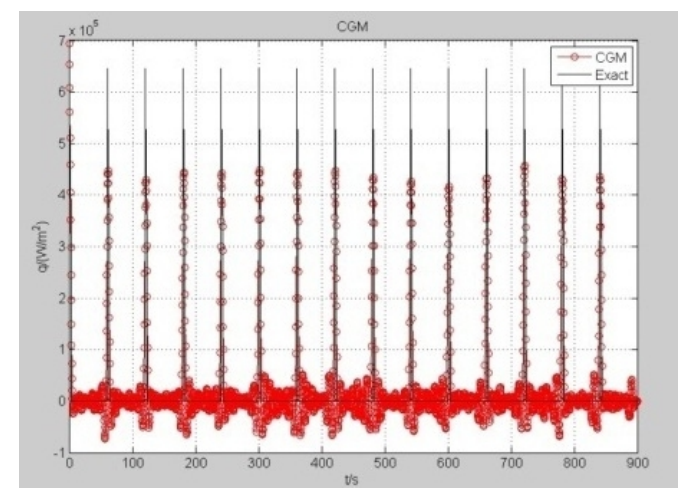

Fig 3.3 heat flux inversion results

For the quantitative analysis of retrieval errors, residuals $S_{R}$ and relative average error $\eta$ is defined as the domain inversion time inversion post.

$$
S_{R}=\sqrt{\frac{1}{K-1} \sum_{k=1}^{K}\left(\hat{R}_{k}-R_{k}^{\text {exa }}\right)^{2}}
$$

$$
\eta=\frac{\sqrt{\frac{1}{K-1} \sum_{k=1}^{K}\left(\hat{R}_{k}-R_{k}^{\text {exa }}\right)^{2}}}{\sqrt{\frac{1}{K-1} \sum_{k=1}^{K}\left(R_{k}^{\text {exa }}\right)^{2}}}
$$

among themR $\mathrm{K}_{\mathrm{K}}$ is the inversion, and $\mathrm{R}_{\mathrm{k}}^{\mathrm{exa}}$ is the actual value.

Thus, according to Formula 3.1 and Formula 3.2, the inversion results can be obtained as shown in Table 31 of the error, the relative error of the mean inversion value with the exact value of 0.45491 .

Table 3.1 Error analysis table

\begin{tabular}{|c|c|c|c|}
\hline$q_{k}^{0}$ & $\sigma$ & $S_{R}$ & $\eta$ \\
\hline 0 & 0.1 & $5.2259 \mathrm{E}+04$ & 0.45491 \\
\hline
\end{tabular}

The inversion of the heat flux is loaded into the brake drum model, calculation of the temperature field distribution, temperature distribution can be obtained in different time. The same time the temperature field of $\mathrm{t}=900 \mathrm{~s}$, and Fig 2.7 shows that the inverse calculation of temperature distribution and accurate temperature distribution is consistent with the brake drum, both the surface temperature was higher than the temperature of the outer surface.

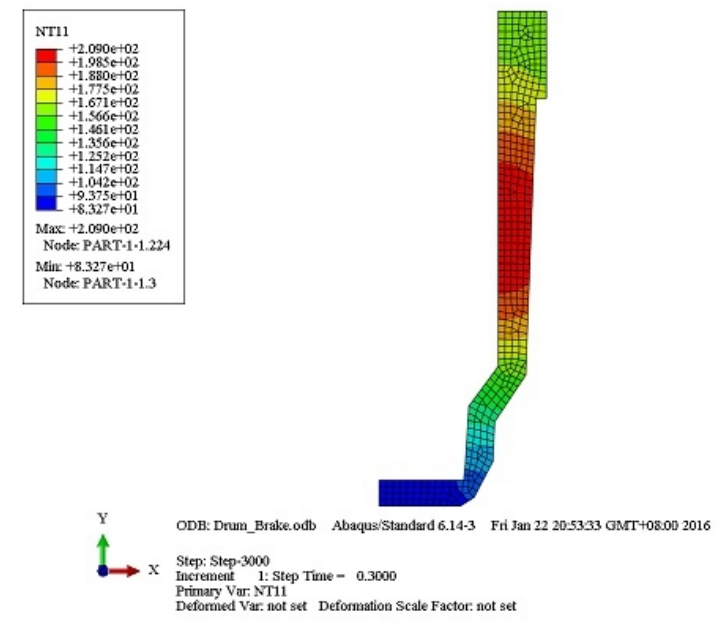

Fig 3.4 T=900s brake drum temperature nephogram inversion results

According to Fig 3.4 shows that, at the time $t=900$ s, the highest point in the temperature of the brake drum node 224, as shown in contrast to the exact point temperature value with inverse temperature values shown in Fig 3.5. Comparative analysis, the fluctuation of the value of inverse consistent with exact values. By this point the relative error of the mean temperature values obtained by inverse to its exact value is 0.0174 , the specific error analysis are shown in Table 3.2. 


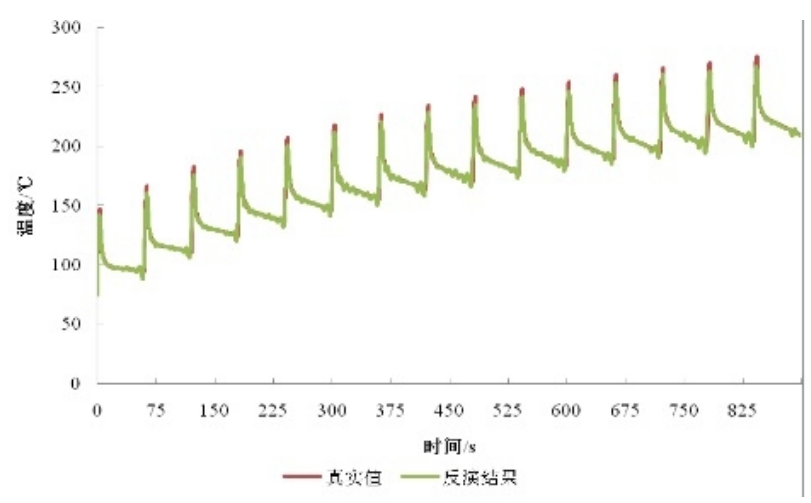

Fig 3.5 The temperature of the inner wall of the node 224 inversion results Table 3.2 Error analysis table

\begin{tabular}{|c|c|c|c|}
\hline$q_{k}^{0}$ & $\sigma$ & $S_{R}$ & $\eta$ \\
\hline 0 & 0.1 & 3.127191 & 0.017441 \\
\hline
\end{tabular}

\section{Conclusion}

Firstly, the establishment of a drum brake temperature mathematical model by ABAQUS finite element analysis software, the brake drum transient temperature field simulation analysis, and then a two-dimensional model of the brake drum as an object, using the theory of inverse heat conduction problem, combined with optimization theory, conjugate gradient method, the establishment of a brake drum Wall heat inversion model. The brake drum outer wall temperature as a basic condition to the brake drum inner wall heat flux distribution as the inversion amount, write procedures using MATLAB calls ABAQUS simulation analysis, and based on the inversion of the heat flow to the brake drum temperature distribution was calculated .

\section{References}

[1] YingxinZhou,ZhihouLi ,Zhongxiang Li, et al. Design of highway emergency Lane [J]., 2010 (05): 206-211.

[2] BinChen, WeiYuan, RuiFu, et al. Downhill traffic accident characteristics analysis [J]. Journal of traffic and transportation engineering continuously grow up, 2009 (04): 75-78.

[3] ZhaomingLuo[D]. of Chongqing University. Heat transfer to study the inverse problem of fuzzy reasoning method, 2014.

[4] Lesnic D, Elliott L, Ingham D B. Application of the boundary element method to inverse heat conduction problems [J]. International Journal of Heat and Mass Transfer, 1996,39(7): 1503-1517.

[5] Su J, Silva Neto A J.. Simultaneous estimation of inlet temperature and wall heat flux in turbulent circular pipe flow[J]. Numerical heat transfer, part A 2001, 40: 751-766.

[6] ChunyanWang. Inverse problem of heat infrared thermal imaging technology based on [D].Soochow University, 2012.

[7] Chunyong Li. T pipe and tube wall temperature inverse heat conduction problem research Beijing University of Chemical Technology [D]. large eddy simulation of fluid mixing process in hot and cold, 2011.

[8] Bo Liu. Inverse heat conduction problem solving temperature fluctuations of the inner wall of [D]. Beijing University of Chemical Technology, 2010 


\section{Introduction to the Authors}

Shun Zeng, male, Han nationality; birth place: Kai xian, Chongqing; birth date: November, 1980; Master Degree, Senior Engineer; Work unit: Chongqing Communications Research \& Design Institute; address: No.33 Xuefu Rd., Nan'an Dist., Chongqing 400067, China; 